\title{
Editorial
}

\section{Panamerican Trauma Society Travelling Scholarship: A Cultural, Clinical and Surgical Exchange}

A major mission of the Panamerican Trauma Society (PTS) is to promote quality continuing education by providing leadership in the creation, development, implementation, and evaluation of a diverse range of educational programs and services. The society also envisions developing and building partnerships with North American and European organizations and institutions to enhance educational opportunities for all its members. Along these lines, the PTS has recently introduced scholarships, such as in disaster management (courtesy of Dr Susan Briggs) and the injury and violence prevention scholarship (generosity of Drs O'Keefe and Aboutanos). The most recent addition is the International Travelling Fellowship, gifted by Dr Paula Ferrada, awarded to North American postgraduate residents or young surgeons to visit high-volume trauma centers in South America and learn from their enormous operative material, under the direct supervision of senior surgical mentors.

This surgical fellowship could not have come at a better time for these young Fellows-in-Training. The present environment is of a drastic reduction of surgical volumes in most North American institutions. The reasons include diminishing numbers of penetrating injuries, increasing trend for nonoperative treatment of blunt trauma and escalating use of nonsurgical approaches to trauma and emergency surgical conditions (e.g. interventional radiology, endovascular approaches). The limited exposure of young surgeons to surgical techniques is very worrisome to training institutions and organizations, since experience as a factor in gaining competence and confidence.

In an attempt to rectify this situation, North American and European organizations like the American College of Surgeons Committee on Trauma and the International Association for Trauma Surgery and Intensive Care have promulgated the use of 1 to 2 days training courses [advanced trauma operative management (ATOM) and definitive surgical trauma care (DSTC)] in surgical skills in the animal laboratory. The PTS has its own surgical skills course (QDT) in the animal laboratory. There also is an attempt to impart surgical training by the application of simulation technologies, a field lead by US military. These initiatives notwithstanding, there is arguably no substitute for formal training in a high-volume center under the direct tutelage of master surgeons, even if only for a short time. Recognizing this, the PTS has taken the next step. Thanks to a generous gift by Dr Ferrada, Co-Chair of the education committee and the progeny of the legendary Ricardo Ferrada, an international scholarship was started for clinical and surgical skills training of North American postgraduate residents. The PTS is no stranger to such unique 'fellowships'. It has a long legacy of surgeons operating in South America with local surgeons, enhancing their own surgical skills. Notable examples include Drs Roriguez, Feliciano and myself.

In this issue of PAJTCCES, Peck, a North American Fellow in acute care surgery, has reported on his pioneering experience as the first PTS international fellow. It is an emotional narration of his rich exposure both to private as well as public institutions in Colombia under the direction of Drs Carlos Ordonez and Ricardo Ferrada. The range of operative procedures in quantity and variety was substantial. Even more impressive and priceless were the cultural exchanges with the Colombian Society. Peck's very personal account of the impact on his family of his absence from home and the potential risk to his physical well-being, and the pain of balancing these against his commitment to his professional goals and ambitions makes for a very poignant reading. It also provides for a very valuable foundation for future fellows. The society is grateful to him for his pioneering efforts and an outstanding account of his fellowship.

In reciprocity for the surgical training of North American residents, the PTS has made available numerous opportunities for latin American health care personnel. They can get an international observer ship program in the areas of critical care, prehospital management and trauma systems in US centers, such as Baltimore, Richmond, Pittsburgh and San Diego. The PTS claims no originality for these outstanding ideas of exchange programs but is keen to embrace and nurture them as the tools for realizing its mission of optimizing global trauma care.

This has been a successful launch but more is on the way. The PTS has an elaborate vision of creating a network of designated training centers with seasoned mentors rather than limited contracts between individual institutions. A streamlined process of application from candidates, meticulous selection of trainees, and a continuous evaluation of the program quality are also a focus of this vision. This is obviously a very ambitious and expensive undertaking, but a very vital one, if trauma care is to be improved in all of our member countries. The society is pursuing all avenues for coming up with the resources, including the creation of a PTS foundation. Generous support from our illustrious members will be counted on for both funds and inspiration!

Rao R Ivatury MD, FACS

Executive Director, PTS Editor-in-Chief, PAJTCCES 